\title{
EFEKTIVITAS METODE NUMBERED HEADS TOGETHER UNTUK MENINGKATKAN KOSAKATA BAHASA INGGRIS PADA SISWA SEKOLAH DASAR DI SEKOLAH $X$
}

\author{
Numbered Heads Together Method Affectivity to Improve English \\ Language Vocabulary for Primary School Students in School X
}

\author{
Vania Priskila ${ }^{1)}$, Heni Mularsih' \\ 1), 2)Program Studi Magister Psikologi, Universitas Tarumanagara
}

Diterima 9 Maret 2020/ Disetujui 15 April 2020

\begin{abstract}
Language is an important aspect in the development stage. Language learning is also applied at the education level even since elementary school education. One of the language lessons published in schools is English. English is not a second language in Indonesia but is included as a foreign language content. The importance of language learning also needs to be balanced with appropriate learning methods so that students enjoy the learning process, one of which is cooperative learning. The purpose of this study was to determine and test the effectiveness of the numbered heads together method to significantly improve English vocabulary in grade 1 elementary school students. The research method used was an experiment with one group pretest-posttest design. The cooperative learning method applied in the implementation of this research is numbered heads together. The results of this study indicate the value of $t=-.889$ and sig. (2-tailed) .415 .
\end{abstract}

Keywords: Vocabulary, cooperative learning, English, numbered heads together

\begin{abstract}
ABSTRAK
Bahasa merupakan aspek yang penting dalam tahap perkembangan. Pembelajaran bahasa juga diterapkan di jenjang pendidikan bahkan sejak pendidikan sekolah dasar. Salah satu pembelajaran bahasa yang dimuat di sekolah adalah Bahasa Inggris. Bahasa Inggris bukan merupakan bahasa kedua di Indonesia melainkan masuk sebagai muatan bahasa asing. Pentingnya pembelajaran bahasa juga perlu diimbangi dengan metode pembelajaran yang tepat agar siswa menikmati proses pembelajaran, salah satunya dengan cooperative learning. Tujuan penelitian ini adalah untuk mengetahui dan menguji keefektifan metode numbered heads together untuk meningkatkan kosakata Bahasa Inggris pada siswa sekolah dasar kelas 1 secara signifikan.Metode Penelitian yang digunakan adalah eksperimen dengan one group PretestPosttest Design. Metode cooperative learning yang diterapkan dalam pelaksanaan penelitian ini adalah numbered heads together. Hasil penelitian ini menunjukkan nilai $\mathrm{t}=-.889$ dan sig. (2-tailed) .415 .
\end{abstract}

Kata Kunci: Kosakata, pembelajaran kooperatif, Bahasa Inggris, numbered heads together

\section{PENDAHULUAN}

Bahasa menjadi salah satu aspek yang penting dalam tahap perkembangan seorang anak. Sebab itu, pendidikan sekolah dasar pun memuat pembelajaran Bahasa, yang salah satunya yakni Bahasa Inggris. Bahasa Inggris penting dipelajari oleh anak sekolah dasar agar anak tidak terkejut ketika menerima pelajaran tersebut di jenjang berikutnya (Maili, 2018). Selain itu, penangkapan suatu Bahasa lebih mudah diterima dengan baik oleh peserta didik sekolah dasar. Santrock (2018), mengatakan bahwa orang dewasa cenderung memelajari bahasa termasuk bahasa kedua lebih cepat, namun level penguasaannya tidak setinggi pada masa kanak-kanak. Hal ini sesuai dengan teori perkembangan yang memandang pemerolehan Bahasa akan diterima lebih baik pada usia sedini mungkin atau bila memungkinkan pada masa kanak-kanak awal.

*Korespondensi Penulis: 
Versi Online: http://journal.ubm.ac.id/index.php/psibernetika DOI: 10.30813/psibernetika. v13i1.2315 Hasil Penelitian

Vygotsky (dalam Santrock, 2018) menyatakan bahwa bahasa memainkan peran kunci dalam proses kognisi. Bahasa dan pemikiran awalnya berkembang secara terpisah, tetapi kemudian diyakini, anakanak akan menginternalisasi egocentric speech mereka ke dalam bentuk inner speech yang pada akhirnya membentuk pemikiran mereka. Transisi ini terjadi antara usia 3 sampai 7 tahun. Terdapat perbedaan apabila Bahasa Inggris dipelajari di rentang usia tersebut dimana pada usia early childhood, anak-anak mendapatkan Bahasa secara tidak sadar atau disebut acquisition, sedangkan semakin beranjak dewasa tidak lagi dapat diperoleh secara tak sadar melainkan melalui proses belajar atau learning.

Bahasa Inggris disebut juga sebagai second language yang dengan sengaja dipelajari guna tujuan tertentu (Brown dalam Fitriyani \& Nulanda, 2017). Namun, pembelajaran Bahasa Inggris di Indonesia sejauh ini masih dianggap sebagas bahasa asing. Pembelajaran Bahasa Inggris di Indonesia sudah ada sejak tahun 1994 baik pada sekolah negeri maupun swasta. Pada mulanya, Bahasa Inggris mengalami perkembangan yang sangat cepat. Namun dari tahun ke tahun, terutama sejak pemberlakuan kurikulum 2013, mulai terdapat kontroversi terhadap pembelajaran Bahasa Inggris. Polemik yang santer terdengar ialah pembelajaran Bahasa Inggris di sekolah dasar akan dihapuskan. Gatra (2017) menyatakan bahwa dalam dunia Pendidikan sekolah dasar, mata pelajaran yang cenderung banyak, tidak diimbangi dengan metode belajar yang kreatif dan menyenangkan bagi anak. Seringnya, metode ceramah oleh guru membuat anak menjadi pasif.

Penelitian terdahulu terkait pembelajaran Bahasa Inggris cukup banyak terutama terkait intervensi yang bertujuan untuk melihat apakah metode atau media tertentu efektif untuk menghafal kosa kata seperti diantaranya penelitian menggunakan flash cards, story card, dsb. Hasil penelitian sebelumnya yang dilakukan oleh Fitriyani dan Nulanda (2017) pada siswa sekolah
Jurnal Psibernetika

Vol. 13 (No.1) : 43 -48. Th. 2020

p-ISSN: 1979-3707

e-ISSN: 2581-0871

dasar menunjukkan adanya perbedaan yang signifikan antara kelompok eksperimen dan kontrol dimana flash cards efektif untuk meningkatkan kemampuan kosa kata Bahasa Inggris pada anak sekolah dasar kelas II. Adapun metode lain yang digunakan seperti story cards juga membuktikan bahwa metode tersebut efektif untuk meningkatkan kemampuan kosa kata Bahasa Inggris pada siswa sekolah dasar kelas III. Dari kedua penelitian ini, peneliti menemukan bahwa siswa sekolah dasar menyukai metode belajar yang berbeda dari biasanya dan kurang menyukai metode ceramah.

Dalam menunjang suatu pembelajaran, terdapat banyak metode yang dirancang atau dikembangkan oleh para pakar Pendidikan. Peneliti menemukan salah satu model pembelajaran yang belakangan marak diterapkan di dunia Pendidikan ialah cooperative learning yang digagas oleh Spencer Kagan. Cooperative learning adalah salah satu bentuk pembelajaran yang didasarkan faham konstruktivis yang berpandangan bahwa anak-anak diberi kesempatan agar menggunakan secara sadar strateginya dalam belajar, sedangkan guru membimbing siswa ke tingkat pengetahuan yang lebih tinggi (Slavin dan Abruscato dalam Ridho 2011). Cooperative learning merupakan model pembelajaran yang melibatkan sejumlah siswa sebagai anggota kelompok kecil dengan tingkat kemampuan yang berbeda. Dalam menyelesaikan tugas kelompoknya, setiap siswa anggota kelompok harus saling bekerja sama dan saling membantu untuk memahami materi pelajaran. Dalam Cooperative learning, belajar dikatakan belum selesai jika salah satu teman dalam kelompok belum menguasai bahan pelajaran.

Dalam model cooperative learning yang dikembangkan Kagan terdapat beragam metode yang dapat diterapkan diantaranya round table, rally robin, one stray, fan $n$ pick, flashcard game, numbered heads together, talking chips, timed pair share dan masih banyak lagi. Diantara semua metode cooperative learning 
Versi Online: http://journal.ubm.ac.id/index.php/psibernetika DOI: 10.30813/psibernetika. v13i1.2315

Hasil Penelitian

tersebut, peneliti menelusuri dan memetakan sesuai dengan tujuan pembelajaran maka metode yang sesuai adalah numbered heads together.

Metode ini dilakukan dengan cara yaitu anak-anak akan diminta untuk berkelompok dan mempelajari masingmasing suatu tema sesuai dengan bagian yang sudah diberikan oleh peneliti (lebih lanjut lihat di lampiran). Bintari (2017) menyatakan bahwa NHT merupakan suatu cara alternatif guru dalam membelajarkan siswa. Pada umumnya NHT digunakan untuk melibatkan siswa dalam penguatan pemahaman pembelajaran ataupun mengecek pemahaman siswa terhadap materi pembelajaran. Sebagian besar aktivitas pembelajaran kooperatif tipe Numbered Heads Together berpusat pada siswa, yakni siswa mempelajari materi pembelajaran sambil berdiskusi untuk memecahkan masalah.

Model pembelajaran NHT merupakan salah satu tipe pembelajaran kooperatif yang menekankan pada struktur khusus yang dirancang untuk mempengaruhi pola interaksi serta memiliki tujuan untuk meningkatkan keaktifan dan hasil belajar siswa. Metode ini sesuai dengan tahap perkembangan pada anak middle childhood yang masih menyukai berkegiatan di dalam kelompok. Selain itu, metode ini merupakan cara menyenangkan bagi anak dan memberikan kesempatan pada anak untuk dapat menjadi pemimpin. Dalam pelaksanaannya juga, peneliti hendak menggunakan media flash cards sebagai sebuah paket intervensi.

Penelitian sebelumnya terkait metode numbered heads together dilakukan oleh Bintari (2017) yakni bagaimana metode tersebut efektif diterapkan dalam pembelajaran matematika. Hasil dari penelitian ini menunjukkan hasil yang signifikan untuk meningkatkan minat belajar siswa. Penelitian lain dilakukan oleh Wijayanti et al (2017) dimana metode NHT dengan regulasi diri yang tinggi memiliki hasil yang efektif untuk hasil belajar mata pelajaran sains. Terdapat cukup banyak penelitian terdahulu menggunakan metode
Jurnal Psibernetika

Vol. 13 (No.1) : 43 -48. Th. 2020

p-ISSN: 1979-3707

e-ISSN: 2581-0871

NHT ini, namun belum ditemukan satupun jurnal yang menyatakan bahwa metode NHT tidak efektif.

\section{METODE PENELITIAN}

\section{Partisipan}

Target partisipan dalam menerapkan dalam penelitian ini yaitu siswa kelas 1 sekolah $\mathrm{X}$ dengan target yaitu sebanyak 6 siswa yang nantinya akan diukur kemampuannya terlebih dahulu sekaligus guna mendapatkan data pretest. Setelah itu akan diberikan treatment dan diikuti dengan posttest.

\section{Teknik Sampling}

Teknik sampling yang digunakan dalam penelitian ini yaitu Teknik purposive sampling di mana partisipan yang dijadikan subjek penelitian sudah ditentukan oleh peneliti berdasarkan karakteristiknya.

\section{Desain Penelitian}

Desain penelitian yang digunakan dalam penelitian ini adalah one group Pretest-Posttest Design, yaitu desain penelitian yang terdapat pretest pada saat sebelum adanya perlakuan dan posttest setelah diberi perlakuan. Dengan demikian dapat diketahui lebih akurat, karena dapat membandingkan dengan diadakan sebelum diberi perlakuan (Sugiyono, 2016).

Hal pertama dalam pelaksanaan eksperimen menggunakan desain ini dilakukan dengan memberikan tes kepada sampel yang belum diberi perlakuan untuk mengontrol subjek dari nilai rata-rata kosakata Bahasa Inggris. Langkah ini dilakukan dengan mencari persentil. Setelah itu dilanjutkan dengan memasangkan anak ke dalam kelompok kecil (berisikan 3 orang) sesuai kesetaraannya, melakukan intervensi dan kemudian memberikan posttest.

\section{Definisi Konseptual}

Kosakata adalah perbendaharaan kata (KBBI, 2016). Sedangkan, metode numbered heads together merupakan metode dimana siswa akan diberikan 
Versi Online: http://journal.ubm.ac.id/index.php/psibernetika DOI: 10.30813/psibernetika. v13i1.2315

Hasil Penelitian

kesempatan untuk saling bergantung di dalam kelompok kecil sehingga terdapat pola interaksi dan bertujuan guna penguasaan di ranah akademik (Kagan, 1992).

\section{Definisi Operasional}

Definisi operasional pada penelitian ini yaitu peningkatan kosakata Bahasa Inggris ialah kapabilitas seseorang di dalam memahami dan me-recall kata-kata yang disajikan dan ditandai dengan siswa kelas 1 SD mampu menyebutkan kembali kata-kata yang dipelajari dengan benar dan tepat. Sedangkan numbered heads together merupakan suatu bentuk metode yang melibatkan adanya pola interaksi antar siswa dengan ditandai adanya suatu kerja sama di dalam kelompok kecil, serta tanggung jawab sebagai pribadi.

\section{Alat Ukur}

Alat ukur yang digunakan merupakan alat ukur yang dibuat sendiri oleh peneliti untuk mengukur aspek penguasaan kosakata siswa kelas 1 SD. Adapun alat ukur atau tes tersebut didesain menjadi matching pictures with words. Hal ini dilakukan peneliti berdasarkan pertimbangan terkait jenis-jenis tes yang sesuai dengan tujuan penelitian yaitu untuk mengukur kemampuan Bahasa. Adapun jenis tes yang sesuai ialah discrete point test yaitu tes untuk mengukur kemampuan seperti grammar, tenses, adverb, prepositions, dan vocabulary. Discrete point test seringnya dalam bentuk pilihan berganda ataupun matching (Benmosteva, n.d).

\section{HASIL DAN PEMBAHASAN}

\section{Hasil Program Intervensi}

Program intervensi dilakukan selama 5 pertemuan. Untuk menguji hipotesis dan mengetahui hasil intervensi ini, peneliti menggunakan paired t-test dengan membandingkan data pretest dan post test.
Jurnal Psibernetika

Vol.13 (No.1) : $43-48$. Th. 2020

p-ISSN: 1979-3707

e-ISSN: 2581-0871

Tabel 1. Gambaran Umum Responden Penelitian

\begin{tabular}{|c|c|c|c|}
\hline Nama & Usia & $\begin{array}{c}\text { Jenis } \\
\text { Kelamin }\end{array}$ & Domisili \\
\hline BRD & $\begin{array}{l}7 \text { Tahun } \\
\text { dan } 5 \\
\text { Bulan }\end{array}$ & Laki-Laki & $\begin{array}{r}\text { Jakarta } \\
\text { Utara }\end{array}$ \\
\hline OWN & $\begin{array}{l}7 \text { Tahun } \\
\text { dan } 9 \\
\text { Bulan }\end{array}$ & Laki-Laki & $\begin{array}{r}\text { Jakarta } \\
\text { Timur }\end{array}$ \\
\hline RNT & $\begin{array}{l}7 \text { Tahun } \\
\text { dan } 8 \\
\text { Bulan }\end{array}$ & Perempuan & $\begin{array}{r}\text { Jakarta } \\
\text { Utara }\end{array}$ \\
\hline GRD & $\begin{array}{l}7 \text { Tahun } \\
\text { dan } 10 \\
\text { Bulan }\end{array}$ & Laki-Laki & $\begin{array}{r}\text { Jakarta } \\
\text { Utara }\end{array}$ \\
\hline AGT & $\begin{array}{l}7 \text { Tahun } \\
\text { dan } 8 \\
\text { Bulan }\end{array}$ & Perempuan & $\begin{array}{r}\text { Jakarta } \\
\text { Utara }\end{array}$ \\
\hline LDA & $\begin{array}{l}7 \text { Tahun } \\
\text { dan } 3 \\
\text { Bulan }\end{array}$ & Perempuan & $\begin{array}{r}\text { Jakarta } \\
\text { Utara }\end{array}$ \\
\hline
\end{tabular}

Di dalam penelitian ini, uji normalitas dilakukan untuk melihat hubungan antar variabel apakah bersifat parametrik atau non-parametrik. Uji asumsi ini menggunakan Shapiro Wilk dikarenakan responden dalam penelitian berjumlah kurang dari 30 orang. Adapun hasil yang didapatkan dari pengujian ini yaitu bahwa data terdistribusi secara normal. Data dapat dikatakan terdistribusi normal yaitu jikaa nilai signifikansi diatas 0.05 ( $p>0,05)$.

Penelitian ini telah selesai dilakukan di mana diketahui bahwa hasil dari pretest dan posttest dalam penelitian ini tidak mengalami perbedaan yang signifikan. Hal ini dapat dilihat dari nilai $\mathrm{t}=$ -.889 dan sig. (2-tailed) .415. Melihat nilai t seharusnya akan menjadi signifikan apabila jumlah subjek lebih banyak. Namun, dari penelitian ini, tetap dapat ditemukan perbedaan nilai antara pretest dan posttest yang mana terdapat suatu peningkatan dari nilai rata-rata walau kecil yakni hanya sebesar 0.5. Pendistribusiannya pun normal dan dipetakan menggunakan Saphiro Wilk dikarenakan jumlah pasrtisipan dibawah 30 . 
Versi Online: http://journal.ubm.ac.id/index.php/psibernetika DOI: 10.30813/psibernetika. v13i1.2315

Hasil Penelitian

Penelitian

menggunakan metode NHT sebagai intervensi memang menujukkan suatu peningkatan secara signifikan. Hal ini juga dapat dipetakan apabila melihat teknik sampling yang lebih kompleks beserta partisipan dengan jumlah yang jauh lebih besar. Bintari (2017) melakukan penelitian terkait bagaimana metode NHT efektif diterapkan dalam pembelajaran matematika. Hasil dari penelitian ini menunjukkan hasil yang signifikan untuk meningkatkan minat belajar siswa. Penelitian lain dilakukan oleh Wijayanti, Roemiyanto, dan Murwaningsih (2017) dimana metode NHT dengan regulasi diri yang tinggi memiliki hasil yang efektif untuk meningkatkan hasil belajar mata pelajaran sains.

Setiap penelitian tidaklah terlepas dari suatu kelemahan. Pada penelitian ini, peneliti menemukan kemungkinan lain sebagai suatu alasan penelitian ini tidak signifikan. Pada saat peneliti melakukan pretest, hasil yang didapatkan oleh anakanak sudah tinggi dan hampir mencapai skor maksimal. Hal ini kemungkinan dikarenakan kemampuan kosa kata siswa SD di sekolah $X$ ini sudah tinggi dan berbeda dengan responden pada saat uji coba. Selain itu, penelitian ini dilakukan pada $2 \mathrm{x}$ hari sabtu dimana anak-anak sedang ada suatu kegiatan di sekolahnya sehingga pada saat pertemuan untuk posttest terdapat beberapa anak yang mengeluh lelah, ingin segera selesai, mempertanyakan mengapa soal yang sama diulang kembali. Meskipun di ruang dan suhu yang sama, pada pertemuan terakhir anak-anak merasa sangat tidak nyaman dengan mengeluhkan panas. Hal ini perlu dimaklumkan mengingat anak SD kelas 1 belum memiliki kemampuan stabilitas emosi yang baik.

\section{SIMPULAN}

Dari penelitian yang telah dilakukan ini, maka dapat disimpulkan bahwa penelitian ini tidak mengalami perbedaan yang signifikan. Hal ini dapat dilihat dari nilai $\mathrm{t}=-.889$ dan sig. (2-tailed)
Jurnal Psibernetika

Vol.13 (No.1) : $43-48$. Th. 2020

p-ISSN: 1979-3707

e-ISSN: 2581-0871

415. Melihat nilai $\mathrm{t}$ seharusnya akan menjadi signifikan apabila jumlah subjek lebih banyak. Namun, dari penelitian ini, tetap dapat ditemukan perbedaan nilai antara pretest dan posttest yang mana terdapat suatu peningkatan dari nilai ratarata walau kecil yakni hanya sebesar 0.5.

Penelitian selanjutnya dapat mengembangkan intervensi ini menggunakan metode lain dari cooperative learning Kagan ini seperti round table, rally robin, one stray, fan $n$ pick, flashcard game, numbered heads together, talking chips, dan timed pair share.

Saran praktis yang dapat diberikan pada penelitian ini ialah agar apabila hendak melakukan intervensi pada siswa SD kelas 1 diperlukan waktu pelaksanaan yang jauh lebih panjang dan diskusi lebih dalam dengan guru terkait kemungkinan yang terjadi dalam pelaksanaan sehingga dapat diatasi sesuai dengan alternatif solusi yang sudah ditetapkan. Waktu observasi lebih lama di dalam kelas juga diperlukan untuk mengenal sifat dan sikap anak dalam proses pembelajaran. Peneliti juga menyarankan agar membuat alternatif soal lain untuk meminimalisir semua kemungkinan-kemungkinan yang dapat terjadi di lapangan.

\section{DAFTAR PUSTAKA}

Bintari, A. (2017). Keefektifan Model Pembelajaran Number Head Together Berbantuan Metode Discovery terhadap Hasil Belajar Matematika. Mimbar Sekolah Dasar, 4(3), 218. https://doi.org/10.17509/mimbarsd.v4i3.7922

Fitriyani, E., \& Nulanda, P. Z. (2017). Efektivitas Media Flash Cards dalam Meningkatkan Kosakata Bahasa Inggris. Psympathic: Jurnal Ilmiah Psikologi, 4(2), 167-182. https://doi.org/10.15575/psy.v4i2.174 4

Gatra, S. (2017, April 27). Mulai juli, sekolah tak boleh kaku! Ini penjelasan mendikbud.

https://nasional.kompas.com/read/201 
7/04/27/11272561/mulai.juli.sekolah.t ak.boleh.kaku.ini.penjelasan.mendikb ud?page=all

Kamus Besar Bahasa Indonesia. (2016). Badan pengembangan dan pembinaan Bahasa. https://kbbi.kemdikbud.go.id/entri/pen didikan

Maili, S. N. (2018). Bahasa Inggris Pada Sekolah Dasar : 6, 23-28.

Ridho, N. (2011). Model pembelajaran kooperatif.

http://Modelpembelajarank_nurridh o_10592.pdf

Santrock, J.W. (2018). Child Development. New York : Mc Grawhill.

Wijayanti, N. W., Roemintoyo, R., \& Murwaningsih, T. (2017). The Impact of Numbered Heads Together Model on the Learning Outcomes of Science Viewed from Students' Self Regulated Learning. Journal of Education and Learning (EduLearn), 11(3), 257. https://doi.org/10.11591/edulearn.v11i 3.5838 